Matta, G., Herrera, R.F., Baladrón, C., Giménez, Z., and Alarcón, L.F. (2018) "Using BIM-based sheets as a visual management tool for on-site instructions: a case study." In: Proc. $26^{\text {th }}$ Annual Conference of the International. Group for Lean Construction (IGLC), González, V.A. (ed.), Chennai, India, pp. 144-154. DOI: doi.org/10.24928/2018/0520. Available at: www.iglc.net

\title{
USING BIM-BASED SHEETS AS A VISUAL MANAGEMENT TOOL FOR ON-SITE INSTRUCTIONS: A CASE STUDY
}

\author{
Gabriela Matta $^{1}$, Rodrigo F. Herrera ${ }^{2}$, Cristóbal Baladrón ${ }^{3}$, Zulay Giménez ${ }^{4}$, and \\ Luis F. Alarcón 5
}

\begin{abstract}
In recent decades, design and construction have had to specialize, which has gradually fragmented the industry. This scenario is relevant in hospital projects, where a large number of specialties interact, especially when the operation of the center must be guaranteed. For this reason, it is essential to reduce the communication time between workers and decision-makers to respond quickly to unexpected problems. The purpose of this article is to describe the use of Visual Management using Building Information Modeling (BIM) to deliver task instructions in the field. A case study of a Chilean healthcare center is described, whereby through the active participation of the consulting team, the use of BIM-based sheets as visual instructions was gradually implemented, taking as input the BIM product and process models. The most relevant results were the fulfillment of the initially estimated deadlines without the delays that historically occurred in these types of projects and the reduction of response times for requests for information. It can be concluded that the use of these BIM-based sheets directly addresses the root causes of information management problems in construction and that it is essential to use technology within a Lean collaborative methodology.
\end{abstract}

\section{KEYWORDS}

Visual Management, BIM, on-site instructions, Lean, healthcare

1 BIM/Lean Project Consultant, Master student, Production Management Consulting - GEPRO, Santiago, Chile, gmatta@gepro.cl

2 PhD candidate, Department of Construction Engineering and Management, Pontificia Universidad Católica de Chile, Professor, School of Civil Engineering, Pontificia Universidad Católica de Valparaíso, Chile, +56 94413 2109, rodrigo.herrera@pucv.cl

3 BIM/Lean Project Consultant, M.Sc., Production Management Consulting - GEPRO, Santiago, Chile, cbaladron@gepro.cl

$4 \mathrm{PhD}$ candidate, Department of Construction Engineering and Management, Pontificia Universidad Católica de Chile, Professor, Civil Engineering, Universidad Centrooccidental Lisandro Alvarado, Barquisimeto, Venezuela, zmgimenez@ing.puc.cl

5 Professor, Ph.D., Department of Construction Engineering and Management, Pontificia Universidad Católica de Chile, Santiago, Chile, lalarcon@ing.puc.cl 


\section{INTRODUCTION}

Studies of construction projects in the field reveal that only $30 \%$ of the work is productive and $70 \%$ are used in activities that do not add value, such as waiting time for instructions, moving materials or finding the right equipment (Elfving 2007); in contrast, acceptable productive time is 60\% (Serpell 2002). Productivity has been shown to be strongly linked to the achievement of sustainable growth and development. In particular, construction productivity has remained stable for decades, unlike the manufacturing industry where productivity has doubled in the same period (Changali et al. 2015).

Current construction projects are becoming increasingly complex and time-bound and require a high level of collaboration between the design team, the developer and the project construction team. To successfully carry out the project, the team faces the challenge of coordinating multiple activities and tasks with numerous specialists in an efficient manner, allowing for increased productivity and a continuous workflow (Koskela et al. 2002).

In recent decades, as a result of the growing complexity of projects, design and construction have had to specialize, leading to a gradual fragmentation in the industry (Dainty et al. 2001; Love et al. 2002), where the number of specialties involved increases in relation to the complexity of the project. Generally, design and construction teams work at different stages of the project, and their interaction is mainly through plans, technical specifications, Request for Information (RFI), etc. (Sacks 2014). This information is dispersed in different documents, with limited structure and available in inadequate visual formats, slowing down processes, hindering information flows and increasing response latency (Mourgues et al. 2007). The workflow described above does not respond to the requirements of current projects, as they demand a high level of interaction requiring new management approaches and technologies to respond to these challenges.

This scenario becomes even more relevant in regard to hospital projects, where a greater number of specialties and their work teams interact, and a high standard of construction quality is required (Dave et al. 2015; Rybkowski et al. 2012). In cases where the project is an extension or remodeling of an existing infrastructure, the difficulty of guaranteeing operational continuity without neglecting the service provided to the patient (brownfield project) is added.

To increase agility and respond rapidly to unexpected problems, it is essential to shorten the communication time between workers and decision-makers (Hamzeh et al. 2012; Mourgues et al. 2012). There is currently software focused on task planning with visual systems that allow stakeholders to work collaboratively (Sacks et al. 2010).

Typical root causes of problems related to information management in construction are as follows: (1) information that is not in a visual format, (2) stratified and unstructured information, and (3) unmanageable digital formats. Table 1 shows the root causes of these problems and links them to the types of waste that is generated (Laine et al. 2014). 
Visual Management (VM) is one of the key elements for the correct implementation of Lean Production, as it provides an easy way to understand the production information (Liker 2003). In recent years, there has been an increase in the use of Building Information Modeling (BIM) in construction; it is therefore interesting to link this methodology with Visual Management (Khanzode et al. 2006).

Table 1: Root causes and waste related to information management in construction (Laine et al. 2014)

\begin{tabular}{|c|c|}
\hline Root cause & Type(s) of waste \\
\hline $\begin{array}{l}\text { Non-visual format: customer and designers cannot perform } \\
\text { functionality review for the whole building with reasonable effort }\end{array}$ & $\begin{array}{l}\text { Waiting, extra processing, } \\
\text { underutilisation of skills }\end{array}$ \\
\hline $\begin{array}{l}\text { Scattered information: defects and inconsistencies in the design } \\
\text { can pass the verification and are found when completing the } \\
\text { work on site }\end{array}$ & Defects, waiting \\
\hline $\begin{array}{l}\text { Non-structured information: most of the information is in } \\
\text { documents and therefore representation is fixed to one format } \\
\text { only }\end{array}$ & Defect, transport \\
\hline $\begin{array}{l}\text { Digital format and devices unsuitable for execution: work on-site } \\
\text { is difficult without using printed and laminated blueprint drawings } \\
\text { and any update requires unnecessary work }\end{array}$ & Motion \\
\hline $\begin{array}{l}\text { The use of the BIM methodology with VM would help to } \\
\text { in Table } 1 \text {. An example of this is the experience reported in th } \\
\text { BIM stations are tools to improve transparency of inforn } \\
\text { stakeholders, where the BIM coordinator keeps the models an } \\
\text { a server (Murvold et al. 2016). }\end{array}$ & $\begin{array}{l}\text { correct the waste identified } \\
\text { use of BIM-station onsite. } \\
\text { lation in the field for all } \\
\text { drawings updated through }\end{array}$ \\
\hline $\begin{array}{l}\text { The objective of this paper is to describe the use of Visual } \\
\text { deliver instructions on the tasks that must and can be done } \\
\text { objective, a case study of a hospital in Chile is described, } \\
\text { participation of the consulting team, the use of visual instr } \\
\text { implemented, using the BIM product and process model as in }\end{array}$ & $\begin{array}{l}\text { Management using BIM to } \\
\text { in the field. To fulfill this } \\
\text { vhereby through the active } \\
\text { ction sheets was gradually } \\
\text { ut information. }\end{array}$ \\
\hline \multicolumn{2}{|l|}{ BACKGROUND } \\
\hline \multicolumn{2}{|l|}{ BUILDING INFORMATION MODELING (BIM) } \\
\hline $\begin{array}{l}\text { For the purpose of this article, we use the BIM definition g } \\
\text { (Eastman et al. 2011), which defines it as a modeling techn } \\
\text { processes to produce, communicate, and analyse buildi } \\
\text { technological developments, BIM is significantly less used } \\
\text { drawings (generated in 2D) still dominate (Murvold et al } \\
\text { common problems associated with 2D-based communication } \\
\text { the considerable time and expense required to generate crit } \\
\text { about a proposed design, including cost estimates, energy- } \\
\text { details. (Eastman et al. 2011). }\end{array}$ & $\begin{array}{l}\text { en in the BIM Handbook } \\
\text { logy and associated set of } \\
\text { models. Despite these } \\
n \text { execution, where paper } \\
\text { 2016). One of the most } \\
\text { during the design phase is } \\
\text { al assessment information } \\
\text { e analysis, and structural }\end{array}$ \\
\hline
\end{tabular}




\section{VISUAL MANAGEMENT (VM)}

Correct representation of information can help mitigate the complexity of production systems, even in chaotic and unpredictable production environments (Kurtz \& Snowden 2003). Therefore, VM tools can be a contribution to on-site construction management. Among the benefits of VM are that it directly supports other management efforts, such as production management, safety management, performance management, and workplace management (cleaning) (Tezel 2011). In addition, the use of VM tools increases the ability to process information and reduces feedback time for action taking, such that control can be integrated into execution (Alvarez \& Antunes 2001). The use of virtual tools improves the transparency of planning, being an instrument for collaborative use in planning and control meetings (Viana et al. 2014). Their other benefits may include greater discipline in the workplace, continuous improvement and work facilitation (Tezel 2013).

\section{INSTRUCTION ON SITE}

Workplace communication is mainly based on 2D drawings and informal verbal explanations. However, due to rework related to incomprehension of design and/or construction information (Mourgues et al. 2007) or errors due to old, incorrect and irrelevant drawings (Harstad et al. 2015), low productivity usually is the result. However, the fast development of information technologies offers new possibilities for portability and access to information on construction sites (Harstad et al. 2015), such as the method of delivering Virtual Huddles information (workstation meetings assisted by Virtual Design and Construction VDC -3D and 4D-) (Mourgues et al. 2007); the use of tablets to achieve communication between design and construction professionals (Harstad et al. 2015); the development of an automated method (FIPAPM, Field Instructions from products and process models) such that the user can produce working instructions based on formats or templates using VDC (Mourgues et al. 2012); or BIM stations, placed on the construction site, where workers can access the information they need, having 3D models available for all (Murvold et al. 2016).

\section{IMPLEMENTATION METHODOLOGY}

To achieve this objective, a case study of a healthcare center in Chile is described. Through the active participation of the consulting team from GEPRO and researchers from the Production Management Center of the Catholic University of Chile (GEPUC), the use of visual instruction sheets was gradually implemented, using the BIM product and the process model as input information. The case study was intervention of consulting team in development of design and construction of the project, for 18 months approximately.

The consulting team was tasked with supporting the owner in project management to ensure deadlines and quality standards. To guarantee the fulfilment of these objectives, Lean and BIM were planned to implement together and form an integrated project team, where owner, designers, contractors and consultants would actively participate. 
Using BIM, it is possible to build precise virtual models of a building, which support design through its different phases, allowing better analysis and control than in a manual process (Eastman et al. 2011). When the models are finished, they contain the geometry and information needed to support the building construction and fabrication processes. The challenge faced by the consulting team was how to bring the information contained in these models to the field clearly, precisely and quickly.

Through experience acquired in other projects, the consulting team was certain that the field workers themselves can provide the best feedback on how to communicate the information extracted from the BIM models. Therefore, based on this feedback and supported by the collaborative environment of the project, different schematics of sheets were iterated, and testing was conducted to include information, such as $2 \mathrm{D}$ drawings and 3D images.

In the following sections of the paper, the case study context is described and then a mixed qualitative and quantitative analysis is presented. The qualitative analysis focuses on the degree of satisfaction of internal clients, participation and commitment in the planning and control meetings, the designer-builder relationship and the response time upon request. The quantitative approach focused on indicators of compliance with the construction deadline and RFI.

\section{CASE STUDY}

\section{CONTEXT}

The case study was developed in a healthcare center in Santiago, Chile, that initially opened in 1982 with a total infrastructure of $15,000 \mathrm{~m}^{2}$. In 2017 , the infrastructure is more than $237,000 \mathrm{~m}^{2}$, growth that has forced the original services to adapt to new capacities. One of these is the hospital kitchen and dining area, which daily serves 500 hospital beds and more than 4,000 employees. This service area of 1,072 $\mathrm{m}^{2}$ had to be remodeled and extended to a surface of $3,040 \mathrm{~m}^{2}$ while maintaining operational continuity and a strict infection control protocol, in addition to complying with an adjusted work schedule.

The brownfield condition of the project, the non-existence of as-built plans with a record of modifications made over time and the poor information on existing installations dating from 1982 made the scenario more complex. For these reasons, the engineering designs initially proposed had to be adapted to what was found in the field during demolitions, generating multiple versions during construction.

Habilitation and construction projects in this healthcare center operated under a traditional workflow, according to Figure 1. The design team, composed of architects and engineers, delivered a set of $2 \mathrm{D}$ plans and technical specifications in text format to the construction team, composed of the contractor and subcontractors. These documents were the main communication tools between the teams. Historically, this workflow brought problems of interpretation, lack of information or verification of constructability, poor coordination between the specialties and lengthy response times, which compromised the execution of the deadline driven project. 
With this incomplete information, the owner ordered design of the main engineering works (climate, electrical, sanitary and sewerage), with the goal of evaluating the technical-economic feasibility of the project, in order to subsequently bid the construction based on a design-bid-build system.

Parallel to the bidding process, the consulting team moved to site permanently to update information of existing infrastructure in-situ, by means of direct observation, as conditions of constructed building made impossible the use of advanced technologies (i.e. laser scanner). With the updated information, BIM model of existing elements was made, that when compared with basic engineering designs revealed incompatibilities and inconsistencies between them. So, it was necessary to adjust the design to achieve a buildable project.

As a result, a coordinated BIM model was already in place in early stages of construction, including existing and planned infrastructure. Model that would be used as a working tool during execution of project.

\section{BIM VISUAL MANAGEMENT PROPOSAL}

Given the project scenario and to ensure its success, it was necessary to change the approach and introduce methodologies and tools to respond to the problems associated with traditional design-build flows. To address the resolution of these problems, it was decided to implement Lean and BIM together as an alternative to the workflow presented in Figure 1. Last Planner System (LPS) techniques and BIM models were indispensable for planning, recording, adapting and coordinating projects in real time. The BIM sheets have been transformed into working instructions for Mechanical, Electrical and Plumbing mounting.
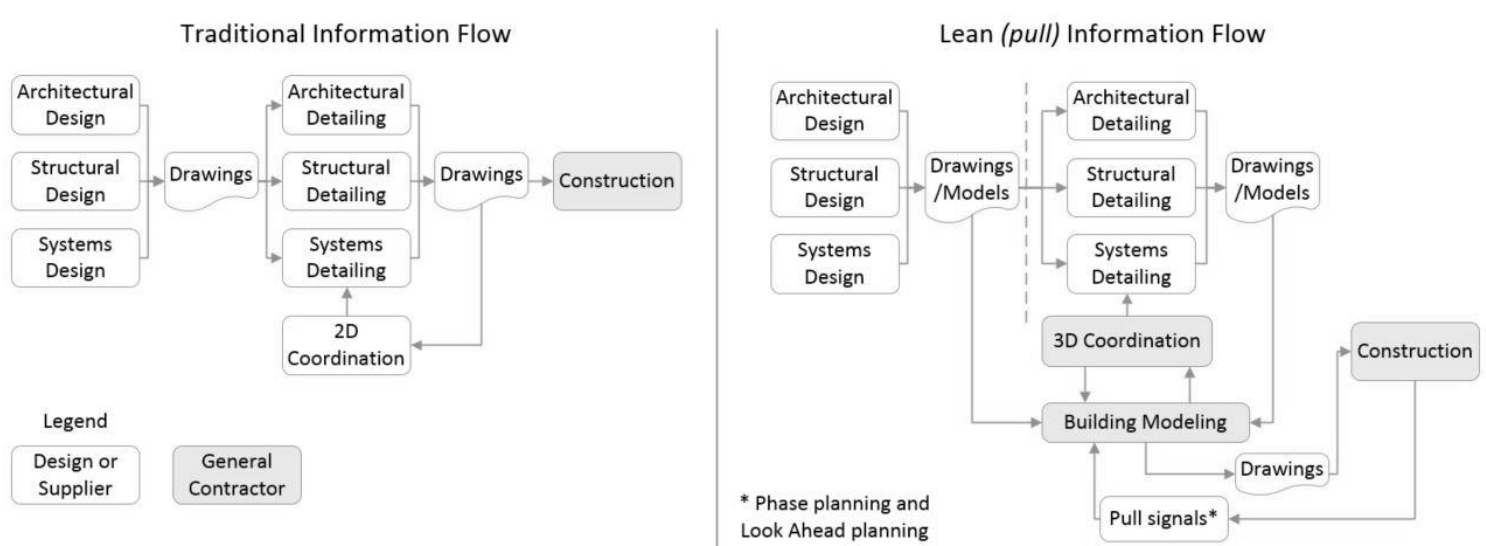

Figure 1: Traditional and Lean (pull) information flow (Sacks 2014)

The new workflow (Figure 1) and the expanded design team (architecture, specialties, client, users and consultants) provides the construction team with a coordinated product model (BIM), which is the main vehicle for communication between the teams. The instruction to generate a BIM sheet comes from a need that is identified in the weekly Last Planner System ${ }^{\circledR}$ (LPS) planning meetings and carried out by the integrated project 
team (extended design team and construction team), and it is based on the work planned for a given period.

As construction progresses, the on-site builders are responsible for the pull signals, determining the BIM sheets that will be required to support the corresponding field work or construction work. Once this signal is emitted, the project's BIM team prepares the sheets for on-site use. These BIM sheets are intended to provide visual information in a consolidated and precise way, under a standard structure and in a format compatible with the execution, since they can be printed in a manageable format (A3) and taken directly to the field. This addresses the root causes of waste related to construction information management, as described in Table 1. The Supplier-Input-Process-Output-Customer (SIPOC) diagram of the BIM sheets process is shown in Figure 2.

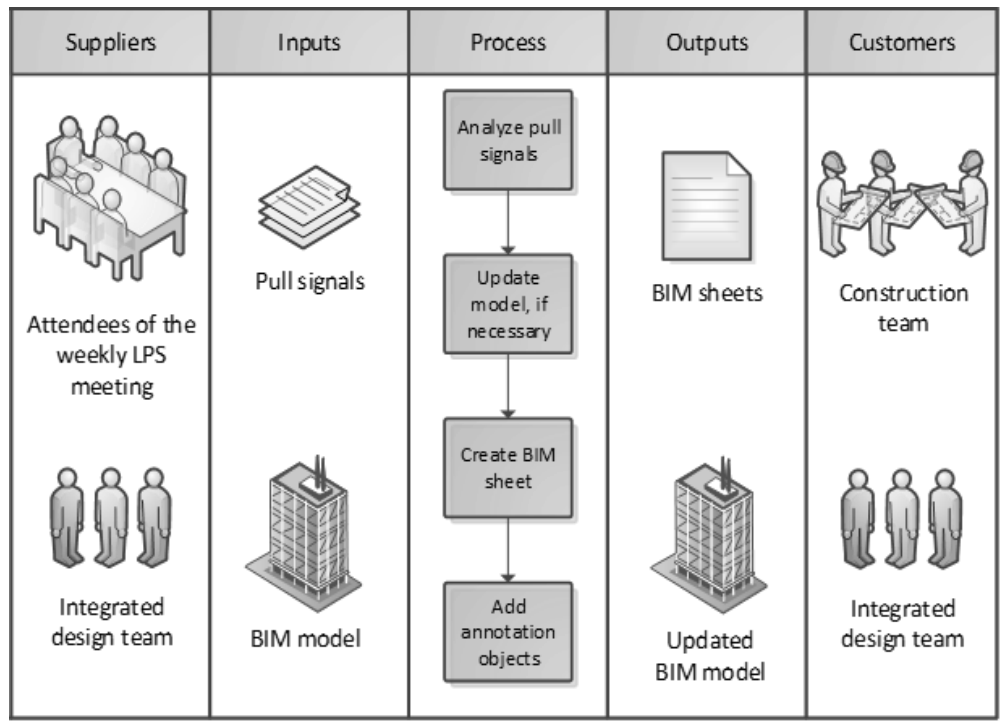

Figure 2: SIPOC diagram of the BIM sheets emission process

Each sheet is presented in an A3 format which contains a series of drawings and images obtained from the updated and coordinated BIM model. Generally, the information contained on these sheets consists of a floor plan, 3D images and sections to effectively communicate the solution of a complex sector of the project (i.e. Figure 3). The elements included in each A3 sheet were defined at the weekly LPS meeting and respond to specific requirements of each sector or specialty.

BIM sheet contains different 3D images and 2D drawings, depending on the need of each subcontract. The previous work of coordinating the designs of the specialties in a BIM model and its previous verification with the installers in the weekly meetings, ensured that in addition to compatible and error-free designs, A3 sheets were obtained with the specific information requested by those who would use them.

This experience was the first incursion of the construction company in the use of LPS to manage planning and BIM for the coordination of specialties, so in conjunction with the consulting team was chosen to use simple means and not too disruptive. 
The final evaluation of the construction company, client, designers, suppliers and subcontractors was positive, highlighting that they achieved greater reliability in the construction processes and certainty of deadlines. In an interview at the end of the process, $76 \%$ of the respondents stated that the use of the cards was decisive in saving time in the field. $46 \%$ stated that they had interacted directly with the model on some occasion to resolve conflicts virtually. Finally, $67 \%$ consider the BIM model and the A3 sheets as a fundamental communication tool in the field.

Considering the initial conditions of the project and the uncertainty at the time of construction, a large amount of RFIs could have been generated, which would have led to continuous review and clarification of problems. With the proposed methodology, the number of RFIs was significantly reduced, as the problem-solving was carried out in the working meetings with the integrated team, recorded in the BIM model and taken to the field in a sheet format. Fifty-six BIM-based sheets were generated in addition to the traditional construction documents (plans, technical specifications, RFI), during the execution of this project over a nine-month period.

The BIM sheet (Figure 3) was used as a systematic communication tool for coordination of specialties and conflict resolution in site. The process and solution embodied in the file, brought together the efforts of all actors promoting a collaborative climate and committed to work, achieving greater integration of the end user, who contributed with their operational experience to improve efficiency in the life cycle and not only during design and construction.

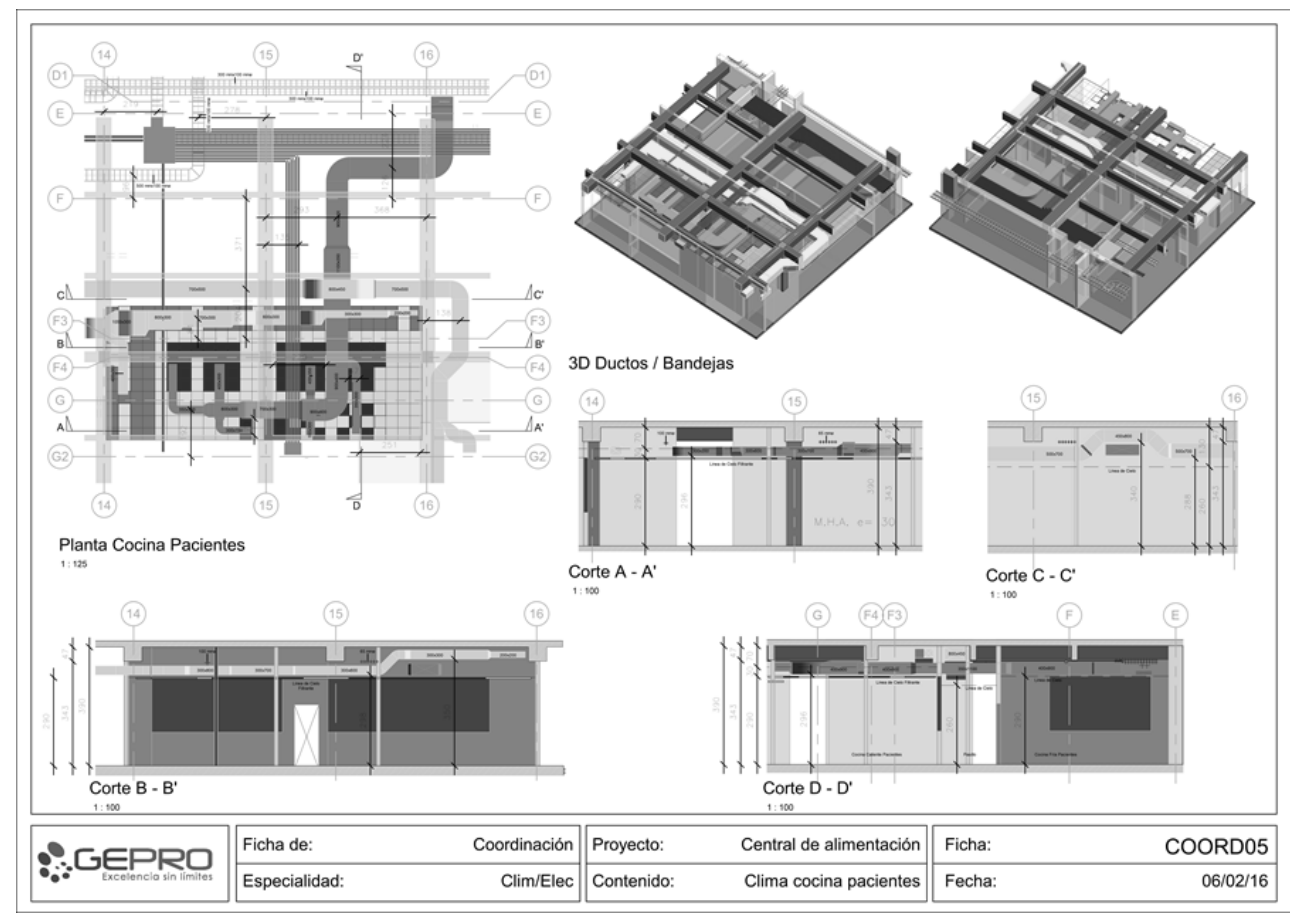

Figure 3: Example of a BIM-based sheet

Among the quantitative data, the estimated deadlines for execution of the work were met without delays. This should be considered a success because in similar projects 
previously carried out by the same client, the project schedules were exceeded by $50 \%$. Further, without the proposed methodology (Figure 1), it was unlikely that the information required in the LPS meeting was available in due time, whereas when implementing the integrated team methodology, pull signals and work instruction sheets, the information was available just-in-time.

\section{CONCLUSIONS}

From the case study we concluded that the use of BIM tools or instruction sheets alone does not guarantee success, time related benefits or reduction of rework. It is necessary to use a collaborative working methodology in which the work processes follow the principles of the Lean philosophy. This is fundamental in complex brownfield projects with multiple and numerous specialists. The use of these sheets directly addresses the root causes of construction information management problems and of the main waste. For example, the tab visually consolidates information, deletes waiting for information, extra processing and defects. This workflow makes sense in projects where the design stages overlap with construction, better known as Fast-Track projects, because the information must be handled in a just-in-time way.

\section{ACKNOWLEDGMENTS}

We acknowledge to GEPRO and GEPUC for supporting this research, the Catholic University of Chile and CONICYT-PCHA/National Doctorate/2016-21160571, for funding the Graduate Researchers. We also thank the healthcare institution for the opportunity to carry out this work.

\section{REFERENCES}

Alvarez, R. Dos R., and Antunes, J. A. V. (2001). "Takt-time: conceitos e contextualização dentro do Sistema Toyota de Produção.” Gestão e produção, 8(1), 118 (in Portuguese)

Changali, S., Mohammad, A., and Van Nieuwland, M. (2015) The construction productivity imperative. Mckinsey http://goo.gl/5gjyju (7Feb2018)

Dainty, A. R. J., Briscoe, G. H., and Millett, S. J. (2001). "Subcontractor perspectives on supply chain alliances Subcontractor perspectives on supply chain alliances." Construction Management and Economics, 19, 841-848. DOI: https://doi.org/10.1080/01446190110089727

Dave, B., Pikas, E., Kerosuo, H., and Mäki, T. (2015). "ViBR - Conceptualising a Virtual Big Room through the Framework of People", Processes and Technology. Procedia Economics and Finance. DOI: http://doi.org/10.1016/S2212-5671(15)002166

Elfving, J. (2007). "Leaning on Planning for Efficient Projects". Skanska World Wide Magazine, 3, 26-27.

Eastman, C., Teicholz, P., Sacks, R. and Liston, K. (2011). BIM handbook: A guide to building information modeling for owners, managers, designers, engineers and contractors. John Wiley \& Sons. 
Hamzeh, F.R., Abi Morshed, F., Jalwan, H. and Saab, I., (2012). "Is improvisation compatible with lookahead planning? An exploratory study." Proc. of the 20thAnn. Conf. of the Int'l Group for Lean Construction San Diego, CA.

Harstad, E., Lædre, O., Svalestuen, F., and Skhmot, N. (2015). "How tablets can improve communication in construction projects." Proc. of the 23rd Ann. Conf. of the Int'l Group for Lean Construction. Perth, Australia, 391 - 401.

Khanzode, A., Fischer, M., Reed, D. and Ballard, G. (2006). "A Guide to Applying the Principles of Virtual Design \& Construction (VDC) to the Lean Project Delivery Process". CIFE Working Paper WP093, Stanford University, CIFE (available at http://cife.stanford.edu/sites/default/files/WP093.pdf)

Koskela, L., Ballard, G., Howell, G., and Tommelein, I., (2002). The foundations of lean construction. In: Best, and de Valence, (2002). Design and construction: building in value. Oxford: Butterworth-Heinemann. pp. $211-226$.

Kurtz, C. F., and Snowden, D. J. (2003). "The new dynamics of strategy: Sensemaking in a complex and complicated world." IBM Systems Journal, 42(3).

Mourgues, C., Fischer, M. and Hudgens, D. (2012). "Method to produce field instructions from product and process models for cast-in-place concrete operations." Automation in Construction, 22, 233 - 246.

Mourgues, C., Fischer, M. and Hudgens, D. (2007). "Using 3D and 4D models to improve jobsite communication - virtual huddles case study". Proc. of $24^{\text {th }}$ W78 Conference, Maribor, 91-96.

Murvold,V., Vestermo, A., Svalestuen, F., Lohne, J. and Læder, O. (2016). "Experience from the use of BIM-Stations" Proc. Of the 24th Ann. Conf. of the Int'l Group for Lean Construction. Boston, MA, USA, 23-32.

Laine, E., Alhava, O. and Kiviniemi, A. (2014). "Improving Built-in Quality by Bim Based Visual Management." Proc. of the 22nd Ann. Conf. of the Int'l Group for Lean Construction. Oslo, Norway, 945-956

Liker, J. (2003). The Toyota Way: 14 Management Principles from the World's Greatest Manufacturer. McGraw Hill Professional.

Love, P. E., Irani, Z., Cheng, E., and Li, H. (2002). A model for supporting interorganizational relations in the supply chain. Engineering, Construction \& Architectural Management, 9(1), 2-15.

Rybkowski, Z. K., Shepley, M., and Ballard, G. (2012). "Target value design: Applications to newborn intensive care units." Health Environments Research and Design Journal, 5(4), 5-23.

Sacks, R. (2014). Can BIM remove waste from construction processes? Tekla European BIM Forum.

Sacks, R., Radosavljevic, R., and Barak, R., (2010). "Requirements for building information modeling based lean production management systems for construction." Automation in Construction, 19(5), 641-655.

Serpell, A. (2002). Administración de Operaciones de Construcción. Alfaomega, México. Tezel, A., Koskela, L.J. and Tzortzopoulos, P. (2013). "Visual Management in Industrial Construction a Case Study." Proc. of the 21th Ann. Conf. of the Int'l Group for Lean Construction. Fortaleza, Brazil, 471-480. 
Tezel, B. A. (2011). Visual management: an exploration of the concept and its implementation in construction. Doctoral dissertation, University of Salford.

Viana, D., Formoso, C., Wesz, J. and Tzortzopoulos, P. (2014). "The Role of Visual Management in Collaborative Integrated Planning and Control for Engineer-to-Order Building Systems" Proc. of the 22nd Ann. Conf. of the Int'l Group for Lean Construction. Oslo, Norway, 775-786. 